\title{
Avaliação institucional: uso de abordagens diversificadas de pesquisa
}

ANA CRISTINA OLIVER*

\section{RESUMO}

O Sistema Nacional de Avaliação da Educação Superior (Sinaes), instituído pela Lei n. 10.861, de 14 de abril de 2004, é formado por três componentes principais: avaliaçáo das instituições (externa e autoavaliação), avaliação dos cursos e avaliação do desempenho dos estudantes. $\mathrm{O}$ objetivo do presente artigo é descrever as várias abordagens de pesquisa utilizadas na autoavaliação de uma instituiçáo de ensino superior particular, para a obtenção dos dados necessários à avaliação das dez dimensôes do Sinaes. O processo de avaliação foi operacionalizado a partir de uma sequência de etapas destinadas à coleta de dados para obtençáo das informaçóes necessárias, a fim de subsidiar o processo analítico da instituição. A coleta de dados constou de questionário eletrônico, vistorias às instalaçôes físicas, reuniôes com os grupos focais (coordenadores, docentes, discentes e corpo técnico-administrativo), entrevistas com os dirigentes e os responsáveis por setores de apoio e suporte às atividades acadêmicas e administrativas e levantamento e pesquisa de documentaçáo e de dados institucionais. Com base nos dados e informaçôes levantados, a comissão fez a compilação, o cruzamento e a análise completa dos dados. A etapa final consistiu da discussão sobre os dados entre os membros da Comissão Própria de Avaliação (CPA) e entre a CPA e os dirigentes, de modo que a comissão pudesse encaminhar um diagnóstico compartilhado sobre as fragilidades, as potencialidades e as açôes a serem realizadas.

Palavras-chaves: Avaliação institucional, Autoavaliação, Avaliação da educação, Ensino superior.

* Mestranda em Ciência de Alimentos da Universidade Federal da Bahia (UFBA), Membro do Grupo de Pesquisa em Educação da Faculdade de Educação da UFBA (ana.oliver@globo.com). 


\section{RESUMEN}

El Sistema Nacional de Evaluación de la Educación Superior (Sinaes), creado por la Ley número 10.861 del 14 de abril del 2004, está formado por tres componentes principales: la evaluación de las instituciones (externa y autoevaluación), la evaluación de los cursos y la evaluación del desempeño de los estudiantes. El objetivo del presente artículo es describir los diversos abordajes de investigación utilizados en la autoevaluación de una institución de enseñanza superior particular, para obtener los datos necesarios para evaluar las diez dimensiones del Sinaes. El proceso de evaluación fue operacionalizado a partir de una secuencia de etapas destinadas al relevamiento de datos para obtener las informaciones necesarias, con el fin de subsidiar el proceso analítico de la institución. La recolección de datos constó de cuestionarios electrónicos, inspecciones a las instalaciones físicas, reuniones con los grupos focales (coordinadores, docentes, discentes y cuerpo técnico-administrativo), entrevistas con los directivos y los responsables de los sectores de apoyo y soporte a las actividades académicas y administrativas, y relevamiento e investigación de documentación y de datos institucionales. Con base en los datos y en las informaciones recolectadas, la comisión hizo la compilación, el cruzamiento y el análisis completo de los datos. La etapa final consistió en una discusión sobre los datos, realizada entre los miembros de la Comisión Propia de Evaluación (CPA) y entre la CPA y los directivos, de modo que la comisión pudiese encaminar un diagnóstico compartido sobre las fragilidades, las potencialidades y las acciones a ser realizadas.

Palabras clave: Evaluación institucional, Autoevaluación, Evaluación de la educación, Enseñanza superior.

\section{ABSTRACT}

The National System of Higher Education Assessment (Sinaes), established by Law Nr. 0,861 of 14 April 2004, consists of three main components: assessment of the institutions (external and self-assessment), evaluation of courses, and assessment of student performance. The aim of this paper is to report on the various survey approaches used in the self-assessment of a private institution of higher education in order to obtain the data needed to evaluate the ten dimensions of Sinaes. The evaluation process was implemented according to a sequence of steps aimed at collecting data to obtain the information necessary to support the analytical process of the institution. Data collection consisted of an electronic questionnaire, inspection of the physical facilities, meetings with focus groups (coordinators, teachers, students and technical-administrative staff), interviews with managers and those responsible for areas of support and assistance to academic and administrative activities, and survey and study of the documentation and institutional data. Based on data and information collected, the committee made the compilation, the comparison and a complete analysis of the data. The final step was the discussion of the data among members of the Own Assessment Committee (CPA) and between the CPA and the managers, so the committee could send a shared diagnosis of the weaknesses, potentials and actions to be taken.

Keywords: Institutional assessment, Self assessment, Assessment of education, Higher education.

14 - Est. Aval. Educ., São Paulo, v. 21, n. 45, p. 13-32, jan./abr. 2010 


\section{INTRODUÇÃO}

A avaliação é uma forma básica do comportamento humano, utilizada no cotidiano de maneira intuitiva e informal. Entretanto, a avaliação formal data de 2000 a.C. no setor público. As autoridades chinesas aplicavam provas aos servidores públicos para avaliar o seu desempenho. Sócrates utilizava avaliaçóes verbais como parte do processo de aprendizado. Por volta de 1950, após a recessão que se seguiu à Segunda Guerra Mundial, os programas sociais cresceram em termos de alcance e escala, tornando necessárias as avaliaçóes constantes (Worthen; Sanders; Fitzpatrick, 2004).

No domínio da educação, a avaliação tem abrangido vários níveis, aspectos e elementos, tais como: alunos, professores, ensino e métodos, até as estruturas educativas, estabelecimentos, programas, currículos e políticas educacionais (Rodrigues, 1999).

Em concordância com o pensamento de Rodrigues, Dias Sobrinho (2003) afirma que na educação a avaliação se firmou não somente como prática política e pedagógica, mas também como importante campo de estudo, produzindo efeitos dentro e fora do âmbito educacional.

As visões sobre avaliação são muito diferentes entre os autores do tema. Essas diversas abordagens surgem em função do conhecimento e visão de mundo dos seus autores que dão diferentes orientações filosóficas e práticas para avaliação (Worthen; Sanders; Fitzpatrick, 2004). Ristoff (2003) reitera essa posição ao afirmar que a definiçáo de avaliaçáo envolve questóes muito complexas.

A complexidade da abordagem do tema avaliação perpassa não somente a definição, mas também sua natureza, as áreas de aplicabilidade, e ainda a finalidade da avaliação. Neste aspecto, o Joint Committee utiliza as palavras "Worth" e "Merit" que significam "valor de mercado" e "valor intrínseco". Essa distinção se faz relevante no meio universitário ou educacional, nos quais o valor náo pode submeter-se única e exclusivamente ao mercado, devendo buscar o valor e as qualidades intrínsecas do objeto (Ristoff, 2003).

Afonso (2005) acredita que a sociologia se incumbe de problematizar a relação da avaliação com os processos de mudança social, e discute a sua utilização como suporte a processos de legitimação política e de regulação ou desregulação que se verifica em diferentes níveis institucionais e na sociedade. $\mathrm{O}$ autor sugere, ainda, que o estudo da avaliação educacional nos remete para diversos enquadramentos e regulamentaçóes legais que ao longo do tempo condicionam a escolha de diferentes sistemas, modelos ou formas de avaliação. Esse estudo ainda deve considerar 
eventuais mudanças nas formas de regulação social que ocorrem em cada país e que são fruto da interação de fatores internos e externos e que atualizam as funçóes da própria avaliação.

Dentre os objetivos da avaliação, estão o de conhecer as fortalezas e os problemas da instituição, adequação do seu trabalho às demandas sociais, envolvimento e compromisso de seus professores, estudantes e funcionários, integração entre teoria e prática, etc. Além disso, é importante identificar as possibilidades reais para a superação das deficiências. No processo de avaliação, é importante dispor de métodos quantitativos e qualitativos para a obtenção das informaçôes. A avaliação externa, combinada com a avaliação interna, ajuda a instituição a identificar seus aspectos mais fortes e suas necessidades gerais, definir as prioridades e verificar o seu desenvolvimento (Dias Sobrinho, 2003).

A avaliação da educação superior deve desenvolver-se baseada nas premissas de que a educação é um bem público e dever do Estado, e a formação e conhecimento são capitais da sociedade, assim as instituiçóes de educação superior têm uma responsabilidade pública e uma finalidade social. Dessa maneira, a avaliaçáo da educação superior deverá ser concebida como um amplo processo de conhecimento, interpretação e atribuição de juízos de valor, além de organização e instauração de açóes e metas para melhorar o cumprimento das finalidades públicas e sociais das instituições (Dias Sobrinho; Ristoff, 2003).

O Sinaes, instituído pela Lei n. 10.861, de 14 de abril de 2004, é formado por três componentes principais: avaliação das instituiçóes, avaliação dos cursos e avaliação do desempenho dos estudantes.

A avaliação das instituições tem como instrumentos a avaliação externa (realizada pelo Inep) e a autoavaliação ou avaliação interna (realizada pela Comissão Própria de Avaliação - CPA), e tem como finalidade o credenciamento e a renovação de credenciamento das Instituiçóes de Ensino Superior. A avaliação dos cursos é realizada periodicamente pelo Inep e tem como objetivo o credenciamento, o reconhecimento e a renovação de reconhecimento dos cursos de graduação. E finalmente o Enade, um exame realizado a cada quatro anos que visa a avaliar o desempenho dos ingressantes e concluintes dos cursos de graduação.

A autoavaliação ou avaliação interna é realizada pela CPA com base na análise das dez dimensóes Sinaes: 1) a Missão e o Plano de Desenvolvimento Institucional (propósitos institucionais, estrutura e processo de construção, aderência à realidade institucional, articulação com o PPI, a gestão e a avaliação institucional); 2) As políticas para a Pesquisa, a Pós-graduação e a Extensão; 3) Responsabilidade

16 - Est. Aval. Educ., São Paulo, v. 21, n. 45, p. 13-32, jan./abr. 2010 
Social (disseminação das atividades científicas, técnicas e culturais; disponibilização, para a comunidade externa, do conhecimento gerado por programas e projetos científicos, técnicos, culturais e artísticos desenvolvidos na unidade; impacto das atividades científicas, técnicas, culturais e artísticas no desenvolvimento regional e nacional quanto à inclusão social, ao desenvolvimento econômico e social, à defesa do meio ambiente, à memória cultural, à produção artística e ao patrimônio cultural. Natureza das relaçóes entre o setor público e privado, existência de projetos de cooperação entre instituições de ensino nacionais e internacionais e açóes voltadas para a promoçáo e o desenvolvimento social interno e externo); 4) Comunicação com a Sociedade (comunicação interna e comunicação externa); 5) Políticas de Pessoal (perfil do corpo docente, condiçóes institucionais, produtividade docente e corpo técnico-administrativo); 6) Organização e Gestão da Instituição (políticas de gestão, estrutura organizacional, mecanismos de participação do corpo social); 7) Infraestrutura física e logística (instalaçôes gerais, biblioteca, laboratórios e instalaçóes específicas); 8) Planejamento e Avaliação (adequação e efetividade do planejamento e procedimentos de avaliação e planejamento); 9) Políticas de Atendimento a Estudantes e Egressos; 10) Sustentabilidade Financeira (política de captação e alocação de recursos e políticas destinadas à aplicação dos recursos).

O objetivo do presente artigo é descrever sobre as várias abordagens de pesquisa utilizadas na autoavaliação de uma instituição de ensino superior particular, para a obtenção dos dados necessários à avaliaçáo das dez dimensões do Sinaes.

\section{AVALIAÇÃO INSTITUCIONAL}

O Sinaes lançou em 2004 o novo sistema de avaliação que abrange todas as instituições de educação superior e ocorre em processo permanente. Sua finalidade é construtiva e formativa e amplia o campo da avaliação quanto à temática, ao universo institucional, aos agentes e aos objetivos.

\footnotetext{
Por ser permanente e envolver toda a comunidade, cria e desenvolve a cultura de avaliação nas IES e no sistema de educação superior. Os agentes da comunidade acadêmica de educação superior, ao participar do processo como sujeitos da avaliação, passam a ficar comprometidos com as transformaçóes e mudanças no patamar de qualidade. (Brasil, 2004, p.7)
}

Um dos componentes básicos do Sinaes, objeto primordial deste documento, é a Avaliação das Instituições de Educação Superior (Avalies), que se desenvolve em dois momentos principais: 
- Autoavaliação, conduzida pelas Comissões Próprias de Avaliação.

- Avaliação externa, realizada por comissóes externas designadas pelo Inep, segundo diretrizes da Conaes.

Cada uma das CPAs é parte integrante do Sinaes, estabelecendo um elo entre seu projeto específico de avaliação e o conjunto do sistema de educaçáo superior do País. Estas comissóes, no desempenho de suas atribuições, serão responsáveis pela "condução dos processos de avaliação internos da instituição, de sistematização e de prestação das informaçóes solicitadas pelo Inep". O papel das CPAs é crucial na elaboração e no desenvolvimento de uma proposta de autoavaliação, em consonância com a comunidade acadêmica e os conselhos superiores da instituição (Brasil, 2004).

A CPA deve contar, na sua composição, com a participação de todos os segmentos da comunidade acadêmica e, também, da sociedade civil organizada, ficando a critério dos órgãos colegiados superiores da instituição as definições quanto ao seu modo de organização, quantidade de membros e dinâmica de funcionamento. Uma vez constituída a CPA, seu funcionamento específico deverá prever estratégias que levem em conta as características da instituição, seu porte e a existência ou não de experiências anteriores de avaliação, incluindo a autoavaliação, avaliaçóes externas, avaliação dos docentes pelos alunos, avaliação da pós-graduação e outros. (Brasil, 2004, p.18)

Para Gadotti (s/d) a avaliação institucional tornou-se preocupação essencial para a melhoria dos serviços das escolas e universidades e para a conquista de maior autonomia. Hoje ela não mais é vista como um instrumento de controle burocrático e centralizaçáo, ela está sendo institucionalizada como um processo necessário da administração, condição para a melhoria do ensino e da pesquisa e exigência da democratização.

Segundo o autor, estabelecer uma filosofia que sirva de base para orientar o processo de avaliação é fundamental para o seu êxito. Sem essa orientação, o processo avaliativo pode se transformar numa atividade rotineira e burocrática sem sentido. "É essa teoria de base que definirá tanto os objetivos quanto o planejamento e os métodos a serem utilizados" (Gadotti, s/d). O autor afirma, ainda, que não basta definir inicialmente se a abordagem será qualitativa ou quantitativa, estabelecer um cronograma de atividades e seu correspondente orçamento.

18 • Est. Aval. Educ., São Paulo, v. 21, n. 45, p. 13-32, jan./abr. 2010 
É impossível administrar uma instituição de ensino com eficiência, justiça e responsabilidade sem um conjunto de informaçóes objetivas confiáveis, que oferece a todos - administração, departamentos, docentes, alunos, funcionários, pais, comunidade - uma visão abrangente das peculiaridades de cada instituição. "Todas as informaçóes devem ser tornadas públicas, devem ser publicadas. E mais: devem ser usadas" (Gadotti, s/d).

Para Marback Neto (2007) "no mundo inteiro os elementos básicos para uma gestão universitária em atendimento às exigências do mercado são: a pertinência, a qualidade, a flexibilidade, a participação e a autonomia no planejamento com foco nos resultados" (p. 142). Ainda segundo Marback Neto, para a gestão, a tomada de decisão é um processo primordial e, como tal, precisa de planejamento, organização, execução e controle e, na universidade, o gestor, principalmente o acadêmico, tem uma gama de decisóes a tomar. Esse autor salienta também que a avaliação institucional é um poderoso e imprescindível instrumento gerencial e pedagógico.

Gatti (2006, p.9) afirma que:

As formas mais disseminadas de avaliação institucional de universidades constituem-se em levantamento de dados na modalidade survey, com um conjunto de questóes sobre categorias consideradas importantes no desempenho de uma universidade (tomado seu conceito de um modo genérico). Os dados recebem um tratamento quantitativo para a construção de indicadores numéricos que passarão a ser tratados como o perfil da instituição e, em geral, discutidos em relação a padrōes pré-definidos, seja internamente por um grupo institucional (o que é raro) ou externamente (no mais das vezes por órgãos governamentais), com base em algumas suposiçôes, ou copiando critérios estrangeiros aplicados a outras realidades.

\section{A autora ainda sustenta que:}

Embora esses procedimentos quantitativos sejam necessários em dadas condiçôes, quando considerados produtores diretos e únicos de informaçáo avaliativa, sem outras reflexôes (por exemplo, em relação ao contexto, a valores sociais e culturais, a impactos de diferentes naturezas, às heterogeneidades sociais, às necessidades locais e regionais, etc.), eles reduzem o escopo da avaliação ao que for passível de ser medido, deixando de lado outras características importantes da atuação de uma universidade, limitando a imagem da instituição a números nem sempre tão significativos como se quer fazer parecer. Isso está ligado a uma 
idéia de "eficiência" abstrata, um tanto despregada do próprio contexto intrauniversidade e comunitário. (Gatti, 2006, p.9)

Para Schofield e Anderson (1984, apud Worthen; Sanders; Fitzpatrick, 2004), a pesquisa qualitativa geralmente é realizada em ambientes naturais, tem o pesquisador como principal instrumento de coleta e análise dos dados, enfatiza a obtençáo de dados reais, concentra-se mais nos processos que nos resultados, emprega vários métodos de dados, principalmente entrevistas e observação dos participantes, etc. A abordagem quantitativa enfatiza a abordagem experimental e os métodos estatísticos de análise, dá ênfase à padronização, precisão e objetividade.

Minayo e Sanches (1993) consideram que do ponto de vista metodológico não há contradição, assim como não há continuidade entre as investigações quantitativa e qualitativa:

A primeira tem como campo de práticas e objetivos trazer à luz dados, indicadores e tendências observáveis. Deve ser utilizada para abarcar, do ponto de vista social, grandes aglomerados de dados, de conjuntos demográficos, por exemplo, classificando-os e tornando-os inteligíveis através de variáveis. A segunda adequa-se a aprofundar a complexidade de fenômenos, fatos e processos particulares e específicos de grupos mais ou menos delimitados em extensão e capazes de serem abrangidos intensamente (p. 247).

Gatti (2006) conclui que a avaliação institucional só ajuda em reais avanços socioeducacionais quando são consideradas não só as questôes técnico-científicas ou de produtos, mas aspectos de gestão e relacionais, aspectos de inserçáo social e de vocaçáo, considerados em uma perspectiva que incorpore novos conceitos, conduzindo à escolha de meios e instrumentos avaliativos, que sejam utilizados de forma a levar à construção de visóes mais integradas acerca do percurso histórico-institucional, em seus envolvimentos concretos.

Buscando a construção dessa visão integrada de uma Instituição de Ensino Superior, descreveremos os processos e instrumentos utilizados em uma autoavaliação institucional, na qual se procurou utilizar abordagens quantitativas e qualitativas, no intuito de analisar grande aglomerado de dados, em razão do tamanho da instituição, e também a complexidade dos seus processos e fenômenos grupais.

20 - Est. Aval. Educ., São Paulo, v. 21, n. 45, p. 13-32, jan./abr. 2010 


\section{A OPERACIONALIZAÇÃO DA AUTOAVALIAÇÃO}

$O$ contexto no qual se insere esta autoavaliação institucional se apresenta da seguinte maneira: uma Instituição de Ensino Superior, faculdade isolada, com vinte e sete cursos de graduação na modalidade presencial, cinco cursos de pós-graduação, sete mil oitocentos e quarenta e sete alunos, setecentos e quarenta e quatro docentes e quatrocentos e cinquenta funcionários.

O processo de avaliação foi operacionalizado a partir de uma sequência de etapas destinadas à obtenção das informaçóes necessárias para subsidiar o processo analítico da instituição. $\mathrm{O}$ processo iniciou-se com uma campanha de divulgação do projeto de Avaliação Institucional da Unidade por meio de um seminário promovido pela Comissão Própria de Avaliação (CPA) para o corpo acadêmico (docentes, discentes e funcionários) da instituição. Em seguida, foi realizada campanha de sensibilizaçáo com visitas às salas de aula e exposição de cartazes, esclarecendo a estrutura e a importância do processo avaliativo.

A etapa de coleta de dados constou de questionário eletrônico, questionário impresso, vistorias às instalaçóes físicas, reuniōes com os grupos focais (coordenadores, docentes, discentes e corpo técnico-administrativo), entrevistas com os dirigentes e os responsáveis por setores de apoio e suporte às atividades acadêmicas e administrativas e levantamento e pesquisa de documentação e de dados institucionais.

Com base nos dados e informaçóes levantados, a comissão fez a compilação, o cruzamento e a análise completa dos dados. A etapa final consistiu da discussão sobre os dados, entre os membros da CPA e entre a CPA e os dirigentes, de modo que a comissão pudesse encaminhar um diagnóstico compartilhado sobre as fragilidades, as potencialidades e as açóes a serem realizadas.

A avaliação institucional tem o objetivo de promover um maior conhecimento da própria instituição, especialmente sob a perspectiva da comunidade interna, para que se possa refletir sobre as fragilidades e potencialidades e assim deflagrar um processo consciente de crescimento e melhoria da qualidade.

Ao finalizar a avaliação institucional com a conclusão do relatório final, algumas consideraçóes foram feitas, no intuito de promover a melhoria do processo avaliativo e por consequência a melhoria da própria instituição. $O$ relatório sobre a análise das dez dimensóes do Sinaes foi apresentado por meio de tabelas com os indicadores correspondentes a cada dimensão. A seguir, serão descritos os processos e instrumentos que subsidiaram a análise de cada uma das dimensões. 


\section{Dimensão 1: A Missão e o Plano de Desenvolvimento Institucional}

Tal dimensão tem como grupo de indicadores: os propósitos institucionais, a estrutura e o processo de construçáo do Plano de Desenvolvimento Institucional (PDI), sua aderência à realidade institucional, sua articulação com o Projeto Pedagógico Institucional (PPI), a gestão e a avaliação institucional.

Para avaliar os propósitos institucionais, foi realizada a leitura e análise do PDI, documento que guiou toda a avaliação institucional, pois se comparou a sua intencionalidade com as açóes realmente efetivadas até então. Nesta etapa procedeu-se apenas à pesquisa documental.

A estrutura e o processo de construção do PDI foram analisados por intermédio da leitura do documento e de grupos focais realizados com toda a comunidade acadêmica, em que se questionou a participação dos seus membros na elaboração do referido documento.

A sua aderência à realidade institucional foi avaliada analisando-se a viabilidade da implementação das propostas do PDI na instituição. A articulação com o PPI também foi analisada com o estudo dos documentos. Já a articulação do PDI com a gestão e a avaliação institucional foi revelada por meio de grupos focais com a comunidade acadêmica e entrevistas com os dirigentes da instituição.

\section{Dimensão 2: As Políticas para a Pesquisa, a Pós-graduação e a Extensão}

Os grupos de indicadores desta dimensão são: o ensino de graduação, o ensino de pós-graduação, a pesquisa e a extensão.

Para a avaliação do ensino de graduação, os seguintes indicadores foram analisados: as políticas institucionais para a graduação e suas formas de operacionalização, bem como a articulação entre o Projeto Pedagógico Institucional (PPI) e os Projetos Pedagógicos dos Cursos (PPC). Para tal intento, foram utilizados como instrumentos de coleta de dados a análise do PDI, PPI e PPC, os grupos focais com discentes, docentes e coordenadores de curso, bem como entrevistas com o corpo administrativo da unidade. Também deram subsídios os dados coletados por meio de questionário eletrônico disponibilizado na internet para a comunidade. Para a análise do ensino de pós-graduação foram utilizados os mesmos instrumentos da graduação.

A análise das políticas para a pesquisa abrangeu as políticas institucionais de práticas de investigação, iniciaçáo científica, de pesquisa e formas de sua opera- 
cionalização e a participação do corpo docente e do corpo discente institucional. Para este intento, foram feitas as análises do PDI, PPI e PPC e verificado o número de alunos e docentes envolvidos com a pesquisa e com a extensão. Além destes, os grupos focais narraram suas formas de operacionalização, na perspectiva do corpo acadêmico.

\section{Dimensão 3: Responsabilidade Social}

Esta dimensão reúne os seguintes grupos de indicadores: 1) nas políticas institucionais, o compromisso da IES com os programas de inclusão social, ação afirmativa e inclusáo digital e as relaçóes da IES com o setor público, o setor produtivo e o mercado de trabalho; e 2) nas atividades de ensino, pesquisa e extensão, a responsabilidade social nessas áreas. Nesta dimensão foi verificada a disponibilização, para a comunidade externa, do conhecimento gerado por programas e projetos científicos, técnicos, culturais e artísticos desenvolvidos na unidade por intermédio dos grupos focais e relatórios dos programas de pesquisa e extensão.

O impacto das atividades científicas, técnicas, culturais e artísticas no desenvolvimento regional e nacional quanto à inclusão social, ao desenvolvimento econômico e social, à defesa do meio ambiente, à memória cultural, à produçáo artística e ao patrimônio cultural foram analisados por meio dos programas de pesquisa desenvolvidos e que atendem a essa demanda.

Quanto à natureza das relações entre o setor público e privado, foram analisadas as parcerias e convênios entre a instituição e outros órgãos e instituições públicas e privadas. A existência de projetos de cooperação entre instituiçôes de ensino nacionais e internacionais foi verificada na entrevista com o responsável por este setor na unidade acadêmica.

As açóes voltadas para a promoçấo e o desenvolvimento social interno e externo foi percebida por intermédio dos grupos focais e das entrevistas com os setores responsáveis, além da verificação do número de açóes implementadas.

\section{Dimensão 4: Comunicação com a Sociedade}

Esta dimensão abrange a comunicação interna e externa. $\mathrm{Na}$ avaliação da comunicação interna os indicadores são: canais de comunicação e sistemas de informaçôes e Ouvidoria. Para coletar os dados para estes indicadores foram utilizados os grupos focais, o questionário eletrônico, a entrevista com os órgãos competentes e a análise do material de divulgação. Já para avaliar a comunicação externa, os indicadores foram 
os canais de comunicação e sistemas de informações e a imagem pública da IES. Para coletar as informaçóes necessárias à análise, foram utilizadas entrevistas, análise do material de divulgação e matérias divulgadas em jornais da regiáo.

\section{Dimensáo 5: Políticas de Pessoal}

A dimensão Políticas de Pessoal abarca as categorias: corpo docente e corpo técnicoadministrativo. Para a categoria "corpo docente", temos como conjunto de indicadores: 1) perfil do corpo docente; 2) condiçóes institucionais e 3) produtividade docente. Para avaliar o perfil do corpo docente foram utilizados os documentos do setor de recursos humanos além de consulta aos coordenadores de cursos. Quanto à produtividade docente, foram preenchidos cadastros com a produçáo docente de acordo com o currículo Lattes de cada um, e para analisar as condiçóes institucionais, os grupos focais e o questionário eletrônico respondido pelos docentes deram bons subsídios.

A categoria "corpo técnico-administrativo" foi analisada em relação às condiçóes institucionais, e os grupos focais e o questionário eletrônico demonstraram o nível de satisfação dos funcionários com a instituição. A análise dos documentos institucionais revelou a existência de políticas para o corpo docente e administrativo da instituiçáo.

\section{Dimensão 6: Organização e Gestão da Instituição}

Nesta dimensão, são analisadas as seguintes categorias: 1) políticas de gestão; 2) estrutura organizacional; e 3) mecanismos de participação do corpo social. $\mathrm{Na}$ primeira categoria temos como indicadores: uso da gestão estratégica para antecipar problemas e soluçóes; modelo de gestão apropriado ao cumprimento das metas e planos de açáo do plano operacional - uso da gestão e processo decisório adequados às finalidades educativas; grau de descentralização administrativa e financeira apropriado; políticas de capacitaçáo, incentivos e benefícios e formas de operacionalização; estrutura e funcionamento do sistema de registro acadêmico; sistema de controle gerencial acoplado ao modelo de gestáo, controle e recuperaçáo de dados e atos institucionais; existência de um Manual de Normas e Procedimentos Acadêmicos e Administrativos em conformidade com a legislação vigente e com deveres e direitos para todos os segmentos da comunidade acadêmica e conhecimento e cumprimento das normas internas pelos distintos segmentos acadêmicos.

Para análise desses indicadores foram utilizadas diversas ferramentas de pesquisa tais como: análise documental, grupos focais, questionário eletrônico, entrevista, consulta ao sistema de controle acadêmico, etc. 
Os indicadores da categoria "estrutura organizacional" são: estrutura organizacional adequada ao modelo de gestão utilizado e que permita o gerenciamento de funçóes em todos os níveis e existência de documentos institucionais contendo a definição clara de cargos e responsabilidades, incluindo um organograma explicitando o relacionamento horizontal e vertical de cargos e funçóes. Para análise de tais indicadores, foram utilizados a pesquisa documental, os grupos focais e o questionário eletrônico.

A categoria "mecanismos de participação do corpo social" foi analisada com base na pesquisa da constituição dos colegiados nos documentos oficias e as atas de reunióes de colegiados. O grupo focal e o questionário eletrônico também colaboraram para uma análise mais completa deste indicador.

\section{Dimensão 7: Infraestrutura Física e Logística}

Nesta dimensão são analisadas as instalações gerais (espaço físico, estrutura voltada para o bem-estar da comunidade acadêmica, equipamentos e serviços); a biblioteca (espaço físico e o acervo) e laboratórios e instalaçóes específicas (espaço físico, equipamentos e serviços). Para avaliar esta dimensão, foi elaborado e aplicado um check list. A satisfação da comunidade acadêmica em relação às instalaçóes físicas foi percebida por meio dos questionários eletrônicos e dos encontros com os grupos focais. Os demais dados (acervo, dimensóes, etc.) foram consultados em documentos e no sistema de arquivos da biblioteca.

\section{Dimensáo 8: Planejamento e Avaliação}

As seguintes categorias foram analisadas: 1) adequação e efetividade do planejamento, cujos indicadores foram: articulação entre o planejamento e a operacionalização do PPI, adequaçáo e efetividade do planejamento geral da unidade, articulação entre o planejamento e os Projetos Pedagógicos dos Cursos; e 2) procedimentos de avaliação e planejamento que têm como indicadores: articulaçáo entre a avaliação e o planejamento, avaliação como ferramenta de acompanhamento do planejamento institucional, condiçóes para o desenvolvimento de um processo efetivo de autoavaliação, participação e comprometimento da comunidade com o processo de autoavaliaçáo, clareza das conclusóes apresentadas no processo de autoavaliaçáo e resultados dos processos de autoavaliação. Para esta análise foram coletados dados por intermédio de análise documental, grupos focais e entrevistas. 


\section{Dimensão 9: Políticas de Atendimento a Estudantes e Egressos}

Esta dimensão tem como categorias os estudantes e egressos. Seus indicadores são: existência de programa de apoio psicopedagógico ao discente, existência de serviços de apoio e supervisão aos estudantes (tutoria e outros), existência de programas de mobilidade e intercâmbio, condiçóes institucionais e produtividade discente. Para os egressos, temos os indicadores: eficiência de formação, educação continuada e acompanhamento de egressos. Para esta análise utilizou-se a análise documental, o questionário eletrônico, os grupos focais e as entrevistas.

\section{Dimensão 10: Sustentabilidade Financeira}

Esta dimensão tem como categorias a sustentabilidade financeira, política de captação e alocação de recursos. Para esta análise, a coleta de dados deu-se basicamente por meio de consulta a documentos e entrevista com a mantenedora e os dirigentes da instituição.

\section{A METAVALIAÇÃo}

Ao finalizar a avaliaçáo institucional com a conclusão do Relatório Final, algumas consideraçóes foram feitas no intuito de promover a melhoria do processo avaliativo e por consequência a melhoria da própria instituição. A CPA teve como elemento facilitador o total apoio da Direção às açóes da comissão. A utilização de novas tecnologias de informação auxiliou enormemente para a conclusão e verificação do levantamento de dados para os relatórios parciais e para o relatório final.

Como relato de algumas dificuldades encontradas a CPA pode apontar a não existência de continuidade do processo avaliativo iniciado anteriormente; a dificuldade de alguns setores em resgatar e disponibilizar os dados e informaçóes institucionais; o número reduzido de membros da comissão, pois dos cinco membros nomeados contou-se com a participação efetiva de apenas dois e ainda assim com um deles tendo atividades paralelas de ensino. A comissão contou também com algumas dificuldades materiais, como a disponibilização de apenas um computador e a não disponibilização de uma impressora na sala da CPA para agilizar a confecção dos documentos. A aquisição de outros materiais, como pastas, CDs, etc., indispensáveis para uma melhor organização e andamento na realização dos trabalhos, foi feita de forma precária.

$\mathrm{Na}$ metavaliação desta $\mathrm{CPA}$, algumas ações são propostas como sugestão para a melhoria do processo avaliativo, podendo ser implementadas pela instituição, tais como: 
- instituir a avaliação como processo sistemático;

- implementação de veículo de divulgação das açóes da CPA (tais como jornal, caderno, página da web);

- instituir mecanismo de coleta de sugestóes para a melhoria do processo;

- participação da CPA em eventos externos sobre avaliação institucional;

- sensibilização maior da comunidade acadêmica para o processo avaliativo;

- articulação permanente da CPA com os diferentes setores acadêmicos e administrativos da faculdade;

- desenvolvimento e implementação de estratégias para ampliar o envolvimento da comunidade com a CPA;

- atualização contínua dos dados institucionais em forma de relatórios e gráficos;

- manutençáo de um local onde sejam reunidos e arquivados os dados das avaliaçóes, bem como os dados e relatórios referentes a cada setor;

- estabelecimento de uma cultura de elaboração de relatório de atividades, por setor e por semestre, onde sejam anexados os dados pertinentes à história da instituição;

- institucionalizar uma cultura avaliativa, mediante articulação dos resultados da avaliação com as açôes institucionais.

\section{RESULTADOS E DISCUSSÃO}

Foi constatado, por meio da avaliação, que a instituição teve um crescimento vertiginoso no número de alunos, em torno de $2.000 \%$, em seus cinco primeiros anos de existência. É natural que com um crescimento dessa ordem, apesar da disposição, do comprometimento e da responsabilidade dos seus gestores, algumas ações administrativas não tenham sido implementadas de maneira eficiente e alguns processos não tenham sido estabelecidos. O período de implantação dos cursos deuse nesses anos iniciais, e na época da avaliação a instituição tinha a maioria de seus cursos implantados na sua totalidade.

No cenário do final da avaliação, o número de alunos tendia a se estabilizar, por causa dos alunos que deixam a instituição, em razão da conclusão do seu curso. $\mathrm{O}$ crescimento quantitativo esperado na graduação deverá ser em relação à diminuição da evasão e ao aumento do número de ingressos pelo vestibular, visando à diminuição do número de vagas ociosas. A instituição pode se voltar, então, para um crescimento em termos de qualidade, de institucionalização dos 
seus processos, de correção das falhas que foram detectadas e de incremento das ações de melhoria. Assim, a avaliação atenderá aos objetivos enfatizados por Dias Sobrinho (2003) que é conhecer suas fortalezas e seus problemas e encaminhar ações de melhoria.

A análise das dez dimensões do Sinaes deu um panorama de que muito já havia sido feito, mas que a instituição ainda tinha muito a realizar, pois a missão institucional aponta qual o caminho a ser trilhado, e a visão da instituição nos mostra um horizonte plenamente atingível com trabalho e dedicação.

Na dimensão 1, A Missáo e o Plano de Desenvolvimento Institucional, a instituiçáo já tinha um novo PDI para o período seguinte, que estava em linguagem clara e com metas realistas, e deveria ser amplamente divulgado e acompanhado para que sua implementação se desse de maneira integral e que as correçóes, se necessárias, fossem efetuadas.

Na dimensão 2, As políticas para a Pesquisa, a Pós-graduação e a Extensáo, o PPI, apesar de ter sofrido algumas alteraçóes, continuava com a mesma essência e foram feitas alteraçôes nos currículos dos cursos para que estes ficassem em total consonância com o projeto pedagógico da instituição.

$\mathrm{Na}$ dimensão 3, Responsabilidade Social, a instituição tinha um belíssimo e relevante trabalho, envolvendo a maioria dos cursos e o entorno social, e apenas algumas açóes de planejamento, divulgação e avaliação de resultados precisariam ser implementadas, para uma valorização maior deste trabalho pela comunidade.

A dimensão 4, Comunicaçáo com a Sociedade, foi avaliada como o ponto de maior preocupação. Necessitava de ações voltadas à melhoria da comunicação interna, um apoio maior do setor de marketing para as açóes promovidas pelas coordenações de curso e um planejamento prévio das ações, para que elas pudessem ser divulgadas de maneira eficiente, tanto interna quanto externamente.

Na dimensão 5, Políticas de Pessoal, a instituição contava com um corpo docente altamente qualificado. Apesar de existir um plano de carreira docente, este não existia na prática e deveria ser implementado para estimular o aprimoramento da prática docente, os trabalhos de pesquisa e o maior engajamento dos professores nas atividades da instituição. Da mesma maneira, o corpo técnico-administrativo também não tinha um plano de carreira institucionalizado, embora, na prática, houvesse um aproveitamento dos próprios funcionários da instituiçáo, para o preenchimento de cargos que promoviam a ascensão profissional. 
Quanto à dimensão 6, Organizaçáo e Gestâo da Instituiçáo, se fazia urgente a necessidade de planejamento de todas as açóes administrativas e acadêmicas e seria recomendável que a gestão se tornasse mais participativa e menos centralizadora e burocrática do que era à época em que foi avaliada. A cultura de preservação da memória da instituição precisava ser resgatada com urgência, e os dados dos setores deveriam ser organizados, atualizados e estar sempre disponíveis para que os órgãos responsáveis pela tomada de decisão pudessem consultá-los.

A dimensão 7, Infraestrutura Física e Logística, atendia perfeitamente à comunidade acadêmica e muitas melhorias tinham sido realizadas em todos os setores. Os laboratórios estavam bem equipados e atendiam à demanda dos cursos. Ao final da avaliação, a instituição já tinha a necessidade de ampliar da sua biblioteca, porém isso já estava previsto para um futuro próximo.

Na dimensão 8, Planejamento e Avaliaçáo, seria necessário um planejamento geral das açôes administrativas e acadêmicas na instituição para evitar açóes de emergência e garantir o cumprimento das metas constantes no PDI. Quanto à avaliação, a manutenção de um órgão que promova avaliações frequentes nos diversos setores e acompanhe as açóes oriundas dos resultados dos processos avaliativos se faz necessária, para garantir a melhoria dos processos.

Na dimensão 9, Políticas de Atendimento a Estudantes e Egressos, os estudantes contavam com um eficiente setor de ouvidoria e a instituição tinha uma boa política de bolsas e descontos. Estava sendo reestruturado o setor de apoio psicopedagógico aos estudantes. Seria conveniente que se instituísse um programa de ajuda aos alunos que têm dificuldade em acompanhar as aulas, para diminuir os índices de reprovação em algumas disciplinas e consequentemente reduzir os índices de evasão por esse motivo. Um programa de acompanhamento de egressos deveria ser implementado o mais rápido possível, para que se pudesse analisar a adequaçáo dos projetos pedagógicos dos cursos ao mercado de trabalho.

Quanto à dimensão 10, Sustentabilidade Financeira, a implantação de prestação de serviços, visando a captação de recursos, que era uma das metas do PDI anterior, não chegou a ser realizada e com a estrutura de laboratórios e a variedade de cursos oferecidos à época, provavelmente não seria difícil a sua implantaçáo. O redimensionamento do quadro acadêmico em 2006 proporcionou estabilidade financeira, porém outros ajustes ainda se faziam necessários, e outras formas de captaçáo de receitas poderiam ser pensadas para equilibrar as perdas com a evasão e a inadimplência. 


\section{CONSIDERAÇÕES FINAIS}

O embasamento teórico para a execução da autoavaliação institucional foi realizado durante o próprio processo de avaliação, em razão do exíguo tempo para a coleta de dados e elaboração do relatório final. Pensando a avaliação nas quatro dimensóes que tratam Guba e Lincoln (1989), pode-se sustentar que a autoavaliação institucional é uma avaliação diagnóstica, cujo foco é o de medida ( $1^{\text {a }}$ dimensão), e verificação do atingimento dos objetivos (2a dimensáo) explicitados no seu Plano de Desenvolvimento Institucional. Para o objetivo da medida, são utilizados instrumentos de coleta que fornecem dados de natureza quantitativa e que são necessários para o conhecimento global da instituição, o nível de satisfação geral da comunidade acadêmica, os índices de produtividade acadêmica, etc. Para esta coleta de dados, o questionário eletrônico, a consulta ao sistema de registro acadêmico, a aplicação de check list, bem como a busca dos dados numéricos, dáo conta de atender a esta demanda.

Pensando na segunda dimensão, que é a do atingimento dos objetivos, os dados coletados são geralmente de caráter qualitativo e aprofundam a busca da compreensão que os agentes envolvidos têm do processo avaliativo, assim como a sua percepçáo e grau de satisfação com os processos institucionais. Para a obtenção desses dados os grupos focais, as entrevistas e a análise dos documentos institucionais são instrumentos adequados.

A terceira dimensão da avaliação, apresentada por Guba e Lincoln (1989), é a da tomada de decisão. Apesar de o relatório final da autoavaliação institucional ser apenas diagnóstico, a compreensão pelos dirigentes institucionais de que este documento é fundamental para a gestão acadêmica e administrativa pode fazer com que ele sirva para a reflexão e tomada de decisão, visando à melhoria do processo. No processo aqui descrito, vários relatórios parciais foram elaborados, para gerar as informaçóes necessárias à construção do relatório final. Acreditamos que a elaboraçáo constante desses relatórios é importante para dar suporte à tomada de decisôes no âmbito das gerências e diretorias acadêmicas e administrativas da unidade, tornando-se uma poderosa ferramenta de gestáo como propóem Gadotti (s/d) e Marback Neto (2007).

A quarta dimensão proposta por Guba e Lincoln (1989) seria a da negociação. Apesar de a autoavaliação institucional ser baseada em critérios que são definidos por órgãos governamentais externos de controle da educação e, portanto, não abre espaço para a negociaçáo, esta dimensão poderia ser retomada quando da socialização dos resultados da avaliação com a comunidade interna, no intuito de construir coletivamente um projeto de melhoria institucional. 
O comprometimento da direção e de toda a comunidade quanto à execuçáo de açóes de curto, médio e longo prazos, para a melhoria da unidade, pode ser garantida por meio de uma avaliação que tenha como princípios a participação, o engajamento e o envolvimento de todos os interessados e a transparência do processo, visando a sua credibilidade.

A avaliação institucional aqui descrita teve por objetivo promover um maior conhecimento da própria instituição, como proposto por Dias Sobrinho (2003), especialmente sob a perspectiva da comunidade interna, para que se possa refletir sobre as fragilidades e potencialidades e assim deflagrar um processo consciente de crescimento e melhoria da qualidade.

A divulgação dos resultados, bem como o comprometimento da direção quanto à execução de açóes de curto, médio e longo prazos para a melhoria da unidade, foram efetivados por intermédio de seminários e jornais de circulação interna.

O quadro 1 demonstra os tipos de abordagem utilizados para a avaliaçáo de cada uma das dez dimensóes do Sinaes.

Quadro 1 - Utilização de abordagens qualitativas e quantitativas para a análise das dez dimensões do Sinaes*

\begin{tabular}{|l|c|c|}
\hline \multicolumn{1}{|c|}{ Dimensões } & Quali. & Quanti. \\
\hline A Missão e o Plano de Desenvolvimento Institucional & $\mathrm{x}$ & \\
\hline As Políticas para a Pesquisa, a Pós-graduação e a Extensão & $\mathrm{x}$ & $\mathrm{x}$ \\
\hline Responsabilidade Social & $\mathrm{x}$ & $\mathrm{x}$ \\
\hline Comunicação com a Sociedade & $\mathrm{x}$ & $\mathrm{x}$ \\
\hline Políticas de Pessoal & $\mathrm{x}$ & $\mathrm{x}$ \\
\hline Organização e Gestão da Instituição & $\mathrm{x}$ & $\mathrm{x}$ \\
\hline Infraestrutura Física e Logística & $\mathrm{x}$ & $\mathrm{x}$ \\
\hline Planejamento e Avaliação & $\mathrm{x}$ & \\
\hline Políticas de Atendimento a Estudantes e Egressos & $\mathrm{x}$ & $\mathrm{x}$ \\
\hline Sustentabilidade Financeira & & $\mathrm{x}$ \\
\hline
\end{tabular}

Como sustentado por Gatti (2006), a avaliação de uma instituição não deve se valer apenas de dados quantitativos, a utilização de abordagens diversificadas de pesquisa permite uma visão abrangente da instituição e a compreensão dos processos que dela fazem parte. Embora de naturezas diferentes, as abordagens qualitativas e quantitativas deram suporte para a construção de uma análise mi- 
nuciosa e resultaram em um documento que serve de base para o conhecimento das fragilidades e potencialidades da instituição, visando à tomada de decisão para a melhoria do processo.

\section{REFERÊNCIAS BIBLIOGRÁFICAS}

AFONSO, A. J. Avaliação educacional: regulação e emancipação. 3. ed. São Paulo: Cortez, 2005.

BARRIGA, A. D. A Avaliação no marco das políticas para a educação superior: desafios e perspectivas. In: DIAS SOBRINHO, J.; RISTOFF, D. I. (Org.). Avaliação e compromisso público: a educação superior em debate. Florianópolis: Insular, 2003.

BRASIL. Congresso Nacional. Lei n.o 10.861 de 14 de abril de 2004. Institui o Sistema Nacional de Avaliação da Educação Superior - Sinaes e dá outras providências. Disponível em: <http:// www.planalto.gov.br/ccivil_03/_ato20042006/2004/Lei/L10.861.htm>. Acesso em: 28 set. 2008.

BRASIL. Ministério da Educação. Comissão Nacional de Avaliação da Educação Superior (Conaes). Diretrizes para a avaliação das instituições de educação superior. Brasília: Inep/Conaes, 2004.

. Avaliação Externa de Instituições de Educação Superior: diretrizes e instrumento. Brasília: Inep/Conaes, 2006.

DIAS SOBRINHO, J. Avaliação da educação superior: regulação e emancipação. In: DIAS SOBRINHO, J.; RISTOFF, D. I. (Org.). Avaliação e compromisso público: a educação superior em debate. Florianópolis: Insular, 2003.

DIAS SOBRINHO, José; RISTOFF, Dilvo. (Org.). Avaliação e compromisso público: a educação superior em debate. Florianópolis: Insular, 2003.

Recebido em: outubro 2009

Aprovado para publicação em: fevereiro 2010
GADOTTI, M. Avaliação institucional: necessidade e condições para sua realização. Rio de Janeiro: UNDIME, p. 7-20. Disponível em: http://www.paulofreire.org/twiki/pub/ Institucional/MoacirGadottiArtigoslt0029/ Avali_Institucional.pdf. Acesso em: 14 set. 2009.

GATTI, B. A. Avaliação institucional: processo descritivo, analítico ou reflexivo? Estudos em Avaliação Educacional, v. 17, n. 34, maio/ago. 2006.

GUBA, E. G.; LINCOLN, Y. Fourth generation evaluation. New Delhi: SAGE, 1989.

MARBACK NETO, G. Avaliação: instrumento de gestão universitária. Vila Velha: Hoper, 2007.

MINAYO, M. C. S.; SANCHES, O. QuantitativoQualitativo: oposição ou complementaridade? Cad. Saúde Públ., Rio de Janeiro, v.9, n. 3, p.239-262, jul./set. 1993.

RISTOFF, Dilvo. Algumas definições de avaliação. In: DIAS SOBRINHO, J.; RISTOFF, D. (Org.). Avaliação e compromisso público: a educação superior em debate. Florianópolis: Insular, 2003.

RODRIGUES, Pedro. A Avaliação como domínio da ciência da educação. In: ESTRELA, A.; NÓVOA, A. (Org.). Avaliações em educação: novas perspectivas. Porto - Portugal: Porto Editora, 1999.

WORTHEN, B. R.; SANDERS, J. R.; FITZPATRICK, J. L. Avaliação de programas: concepções e práticas. Tradução Dinah de Abreu Azevedo. São Paulo: Gente, 2004.

32 - Est. Aval. Educ., São Paulo, v. 21, n. 45, p. 13-32, jan./abr. 2010 